\title{
PENDAMPINGAN PEMBUATAN E-MODUL SIGIL SOFTWARE BERBASIS CONTENT LANGUAGE INTEGRATED LEARNING (CLIL) PADA PEMBELAJARAN BAHASA INGGRIS SMK DI KABUPATEN KARAWANG
}

\author{
Nina Puspitaloka1), Zaenal Arifin'2), Purwantoro) \\ 1)Pendidikan Bahasa Inggris, Fakultas Keguruan dan IImu Pendidikan, Universitas Singaperbangsa Karawang, \\ Karawang, Jawa Barat, Indonesia \\ 2)Pendidikan Agama Islam, Fakultas Agama Islam, Universitas Singaperbangsa Karawang, Karawang, Jawa Barat, \\ Indonesia \\ ${ }^{3)}$ Teknik Informatika, Fakultas IImu Komputer, Universitas Singaperbangsa Karawang, Karawang, Jawa Barat, \\ Indonesia
}

Corresponding author : Nina Puspitaloka

E-mail : nina.puspitaloka@fkip.unsika.ac.id

\section{Diterima 24 November 2021, Direvisi 01 Desember 2021, Disetujui 01 Desember 2021}

\begin{abstract}
ABSTRAK
Kemajuan teknologi membangun perubahan dalam berbagai bidang, khususnya dalam bidang pendidikan. Semua elemen dalam bidang tersebut dituntut untuk dapat memanfaatkan perkembangan teknologi, seperti hal nya guru yang harus mampu beralih dari penggunaan modul cetak ke modul elektronik (e-modu). Tujuan dari pelaksanaan program pengabdian masyarakat ini adalah untuk meningkatkan dan melatih keterampilan teknologi para guru bahasa Inggris SMK di Karawang. Kegiatan pengabdian kepada masyarakat ini dilakukan dengan memberikan pendampingan membuat e-modul interaktif berbasis Content Language Integrated Learning (CLIL) menggunakan Sigil Software kepada 15 orang guru Bahasa Inggris SMK di Karawang. Pendampingan pembuatan e-modul ini dilakukan dengan metode ceramah, tanya jawab, serta praktik pembuatan e-modul. Kegiatan ini dilaksanakan di laboratorium komputer SMK Saintek Nurul Muslimin. Hasil dari pelaksanaan kegiatan ini menunjukan bahwa program pengadian kepada masyarakat mampu meningkatkan kompetensi para guru bahasa Inggris dalam penguasaan materi dan pengajaran sesuai dengan jurusan bidang keahlian di sekolah. Selain itu, dapat memberikan manfaat yang sangat besar dan tepat sasaran bagi guru Bahasa Inggris. Bentuk pendampingan seperti ini merupakan bentuk yang sangat efektif untuk memberikan tambahan wawasan serta pengetahuan baru di bidang teknologi informasi di luar proses pembelajaran yang sekolah berikan untuk meningkatkan kualitas guru.
\end{abstract}

Kata kunci: bahasa inggris; content language integrated learning (clil); e-modul; pendampingan; sigil software.

\begin{abstract}
The Advances in technology build changes in various fields, especially in the field of education. All elements in these fields can take advantage of technological developments, such as teachers who must be able to switch from using print modules to electronic modules (e-modules). This community service activity is carried out by providing assistance in the form of interactive e-modules based on Content Language Integrated Learning (CLIL) using Sigil Software to 15 English Vocational High School teachers in Karawang. Assistance in the manufacture of e-modules is carried out by means of lectures, questions and answers, and the practice of making e-modules. This activity was carried out in the computer laboratory of SMK Saintek Nurul Muslimin. The purpose of implementing this community service program is to improve and train the technology skills of vocational English teachers in Karawang. The results of the implementation of this activity show that the community service program is able to improve the competence of English teachers in mastering the material and teaching in accordance with the field of expertise at school. In addition, it can provide enormous and targeted benefits for English teachers. This form of assistance is a very effective form of providing additional insight and new knowledge in the field of technology outside of the learning process provided by schools to improve the quality of teachers.
\end{abstract}

Keywords: assistance; e-modul; english language; content language integrated learning (clil); sigil software. 


\section{PENDAHULUAN}

Perkembangan teknologi membangun perubahan dalam berbagai bidang, termasuk bidang pendidikan. Semua elemen dalam bidang pendidikan dituntut untuk dapat menguasai perkembangan teknologi (Sari, 2020), seperti hal nya guru yang harus mampu beralih dari penggunaan modul cetak ke modul elektronik (e-modul). Penggunaan teknologi tentunya membutuhkan usaha untuk dapat beradaptasi terhadap keefisiensian dan keefektifan pembelajaran agar dapat meningkatkan kualitas pembelajaran (Bahri et al., 2021). Penggunaan teknologi juga membutuhkan kecakapan teknologi yang baik untuk digunakan pada latar pendidikan (Bllaca, 2016). Selaras dengan hal tersebut, tentunya guru sebagai satu satu nya elemen yang mendidik siswa didalam kelas dituntut untuk dapat memaksimalkan teknologi dalam kegiatan belajar mengajar.

Teknologi mempermudah guru maupun siswa untuk mengakses beragam informasi pembelajaran kapanpun dan dimanapun. Saat ini sudah banyak sekali modul elektronik dan buku elektronik yang dapat didownload secara gratis sehingga tidak perlu lagi mengeluarkan uang untuk membelinya dalam bentuk cetak. Walaupun demikian, penggunaan dan isi modul harus disesuaikan dengan keadaan kelas di sekolah. Oleh karena itu, guru berperan penting pada pengembangan modul agar dapat mencapai tujuan pembelajaran. Selain itu guru juga berperan sebagai fasilitator dalam membantu siswa untuk meningkatkan minat dan motivasi siswa dalam belajar bahasa Inggris (Samodro, 2019). Namun faktanya masih banyak guru SMK yang belum mengembangkan bahan ajar atau modul sesuai dengan kebutuhan siswa SMK (Masyhud, 2021), khususnya pada guru mata pelajaran Bahasa Inggris. Hal tersebut juga terjadi pada Sekolah Menengah Kejuruan yang menjadi tempat program Pengabdian Kepada Masyarakat penulis. Pada praktik pengajaran Bahasa Inggris nya terdapat ketidaksesuaian keterampilan bahasa Inggris dengan materi yang diajarkan. Selain itu media pembelajaran yang digunakan juga belum menggunakan media berbasis teknologi serta materi ajar yang ditemukan tidak relevan dengan pengetahuan program keahlian di SMK. Hal ini perlu adanya kerja keras guru mata pelajaran Bahasa Inggris untuk dapat meningkatkan hasil belajar Bahasa Inggris sesuai dengan yang diharapkan (Surjono \& Susila, 2013). Peran sekolah dan guru juga sangat penting untuk proses pengembangan potensi peserta didik (Sarmini et al., 2021).

\section{Program Pengabdian Kepada} Masyarakat ini dilakukan bagi guru-guru Bahasa Inggris Sekolah Menengah Kejuruan (SMK) di Kabupaten Karawang. Pelaksanaan program ini dilakukan di salah satu SMK di Karawang, yaitu Sekolah Menengah Kejuruan Saintek Nurul Muslimin, yang merupakan salah satu SMK swasta yang berlokasi di daerah Batujaya. Pemilihan SMK Saintek Nurul Muslimin Karawang sebagai tempat pendampingan karena sekolah ini merupakan salah satu Sekolah Menengah Kejuruan yang ditunjuk sebagai Center of Excellence (COE), dimana program ini merupakan program pengembangan pusat keunggulan bagi SMK yang bertujuan untuk meingkatkan mutu pendidikan SMK. Sekolah Menengah Kejuruan yang dipilih sebagai sekolah COE akan difasilitasi sarana dan prasarana, seperti gedung COE yang dibangun untuk SMK Saintek Nurul Muslimin ini.

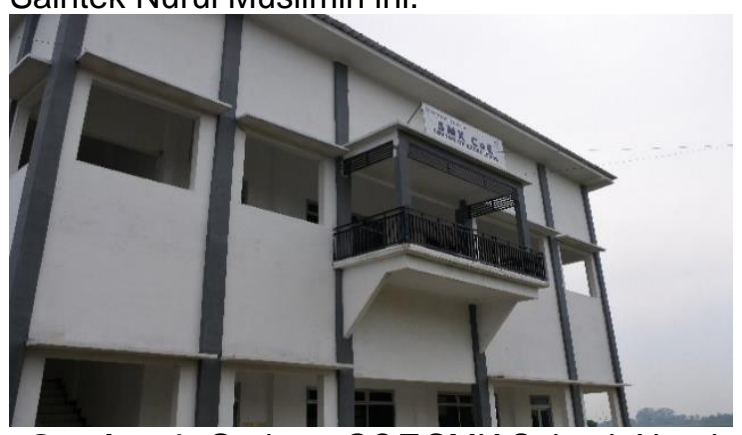

Gambar 1. Gedung COE SMK Saintek Nurul Muslimin (Sumber : Pribadi).

Sekolah-sekolah menengah kejuruan memiliki beberapa bidang kejuruan seperti, Teknik Komputer dan Jaringan (TKJ), Rekayasa Perangkat Lunak (RPL), Teknik dan Bisnis Sepeda Motor (TBSM), Perbankan Syariah (PS), dan lainnya. Akan tetapi, pada praktik pembelajaran Bahasa Inggris yang berlangsung di sekolah-sekolah menengah kejuruan masih termasuk kedalam kategori umum dimana belum ada pembelajaran Bahasa Inggris yang dikhususkan sesuai dengan bidang kejuruan. Hal ini sangat disayangkan, karena guru - guru Bahasa Inggris di Sekolah Menengah Kejuruan yang masih menggunakan coursebook yang tidak menunjang kebutuhan siswa. Materi yang terdapat dalam coursebook tersebut lebih menekankan kepada grammar bukan pada communicative competence. Pada akhirnya, siswa tidak mempunyai pengalaman belajar yang sesuai dengan bidangnya. Hal inilah yang menjadi faktor penyebab ketidaksesuaian antara kompetensi akademik lulusan sekolah kejuruan dengan tuntutan dunia kerja yang menyebabkan banyak lulusan SMK yang tidak terserap didunia kerja profesional. Padahal 
siswa lulusan SMK harus siap bersaing di dunia industry (Masyhud, 2021). Tantangan ini menuntut SMK harus dapat berorientasi pada permintaan kebutuhan dunia industri. Hal ini sejalan dengan Puspitaloka, N. (2020) dengan judul PKM nya: "Pelatihan Basic English for Computing untuk Siswa SMK Teksas Purwakarta" yang menyatakan bahwa English for Spesific Purposes (ESP) merupakan sebuah pendekatan dalam pembelajaran bahasa Inggris untuk bidang dan kajian khusus yang sesuai dengan kebutuhan bidang ilmu yang dikaji dan profesinya.

Berdasarkaan fenomena tersebut, permasalahan yang terjadi di SMK merupakan permasalahan yang mendesak untuk dapat segera diatasi. Oleh karena itu, program pendampingan pembuatan e-modul sigil software berbasis Content Language Integrated Learning (CLIL) pada pembelajaran Bahasa Inggris SMK mampu memberikan solusi terhadap fenomena permasalahan yang terjadi saat ini. Solusi yang ditawarkan untuk mengatasi fenomena tersebut adalah dengan melalukan sosialisasi pembuatan e-modul sigil software berbasis Content Language Integrated Learning (CLIL) bagi guru-guru bahasa Inggris SMK di Kabupaten Karawang.

Program pengabdian kepada masyarakat ini bertujuan untuk memberikan pendampingan pembuatan e-modul Sigil Software berbasis Content Language Integrated Learning (CLIL) bagi guru-guru bahasa Inggris SMK di Kabupaten Karawang. Kegiatan ini dapat menjawab beberapa permasalahan mitra terkait pembelajaran bahasa Inggris di sana, yaitu (1) ketidaksesuaian materi bahasa Inggris pada bahan ajar, dan (2) ketidaksesuaian media pembelajaran yang digunakan. Hasilnya, pembelajaran didalam kelas dapat berjalan secara optimal sehingga pembelajaran Bahasa Inggris dapat sesuai dengan kejuruan dan kebutuhan siswa. Selain itu juga kegiatan belajar mengajar dapat mencapai tujuan pembelajaran.

\section{METODE}

Sebagai bentuk untuk merealisasikan solusi yang ditawarkan dan menyelesaikan fenomena permasalahan yang ada maka dilaksanakanlah kegiatan pendampingan pembuatan e-modul interaktif berbasis android dengan menggunakan Sigil Software. Metode yang digunakan dalam Pengabdian Kepada Masyarakat ini adalah dengan ceramah, tanya jawab, serta praktik langsung pembuatan $e$ modul Bahasa Inggris. Program pendampingan ini dilakukan di laboratorium komputer SMK Center of Excellence (COE) Saintek Nurul
Muslimin yang berlokasi di Teluk Bango, Batujaya, Karawang.

Tim pengabdian terdiri atas 3 orang dan melibatkan 4 orang mahasiswa, sedangkan peserta program pendampingan ini melibatkan 15 orang guru Bahasa Inggris SMK di Kabupaten Karawang. Metode pelaksanaan pada kegiatan pengabdian kepada masyarakat ini dengan menggunakan dua tahapan yang dilakukan, yaitu pra-kegiatan dan pelaksanaan kegiatan.

\section{Pra-Kegiatan}

Dalam tahapan ini dilakukan rapat strategi pelaksanaan kegiatan yang dipimpin oleh ketua pelaksana Pengabdian Kepada Masyarakat (PKM) untuk membahas mengenai perencanaan program pendampingan. Kemudian tim PKM melakukan survei tempat pelaksanaan program pendampingan yaitu SMK Saintek Nurul Muslimin. Tujuan melakukan survei adalah untuk mengatur tempat pelaksaan kegiatan, perlengkapan yang dibutuhkan, dan bentuk kegiatan yang akan dilaksanakan. Dalam tahap ini juga tim PKM dan mitra terkait mempersiapkan sarana dan prasarana untuk medukung pelaksaan kegiatan pendampingan. Sarana lainnya yang dipersiapkan oleh tim PKM dalam tahap ini secara bertahap, yakni: pembuatan spanduk kegiatan, peminjaman proyektor, dan peminjaman sound system.

\section{Pelaksanaan Kegiatan}

Tahap pelaksanaan kegiatan adalah tahap utama dari program pengabdian kepada masyarakat ini. Peserta dalam kegiatan pelatihan dan pendampingan pembuatan $e$ modul Sigil Software pada pembelajaran Bahasa Inggris adalah guru guru yang mengampu mata pelajaran Bahasa Inggris SMK di Kabupaten Karawang. Teknis pelaksanaan kegiatan pendampingan ini adalah pemateri memberikan penjelasan terlebih dahulu tentang Sigil Software, praktik pembuatan e-modul, dan tanya jawab. Setelah tahap pelaksanaan, tim PKM juga melakukan tahap evaluasi guna mengetahui keberhasilan kegiatan tersebut. Tahap evaluasi yang dilakukan adalah dengan melakukan wawancara langsung kepada peserta pelatihan dan observasi saat kegiatan berlangsung untuk mengetahui respon dan partisipasi peserta saat mengikuti rangkaian kegiatan.

\section{HASIL DAN PEMBAHASAN}

Berikut adalah hasil yang telah dicapai dalam pendampingan pembuatan e-modul Sigil software berbasis Content language Integrated Learning (CLIL) pada pembelajaran bahasa 
Inggris untuk guru SMK yang diikuti oleh 15 orang guru Bahasa Inggris SMK di Kabupaten Karawang. PKM ini dilaksanakan sebanyak tiga kali pertemuan setiap hari Sabtu, yaitu tanggal 23 Oktober, 30 Oktober, dan 6 November 2021 yang berlokasi di SMK SAINTEK Nurul Muslimin Batujaya Karawang.

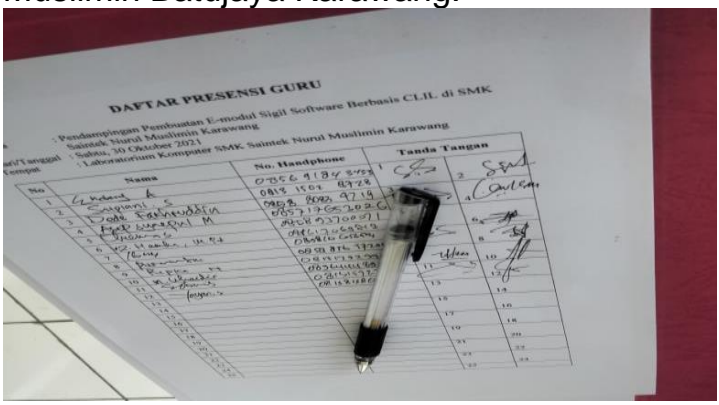

Gambar 2. Daftar Presensi Peserta PKM (Sumber : Pribadi).

Pelaksanaan pendampingan pembuatan e-modul ini dilakukan untuk menjawab tantangan era teknologi saat ini. Selaras dengan hal tersebut, saat ini modul yang pada umumnya disajikan dalam bentuk media cetak dengan hadirnya teknologi elektronik, modul kini dapat disajikan dalam bentuk digital atau disebut dengan e-modul. EModulmerupakan salah satu media yang efektif, efisien, dan mengutamakan kemandirian siswa (Fitri, 2019). Pembuatan dan pengembangan modul maupun e-modul dapat dilakukan oleh guru karena modul merupakan sumber bahan ajar yang disesuaikan dengan kebutuhan siswa didalam kelas. Maka dengan adanya pendampingan pembuatan e-modul ini guru mendapatkan manfaat yang besar untuk dapat membuat e-modul nya sendiri sehingga pembelajaran didalam kelas menjadi lebih efektif dan efisien.

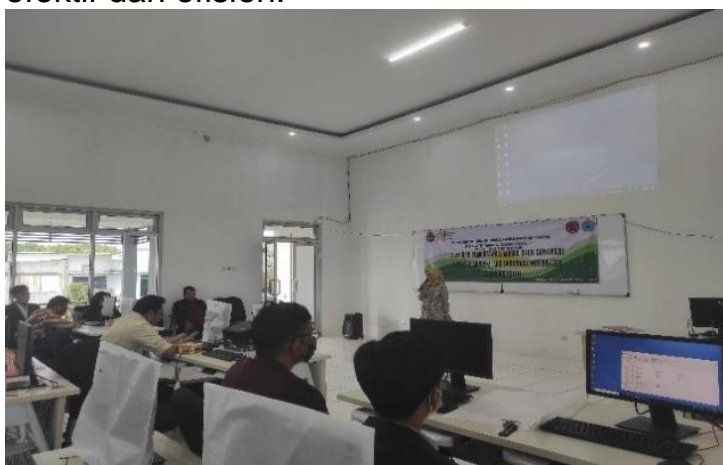

Gambar 3. Tim PKM Memberikan Pengarahan Sebelum Kegiatan Pendampingan (Sumber : Pribadi).

Ketua pelaksana pengabdian kepada masyarakat memberikan arahan dan penjelasan singkat mengenai kegiatan pendampingan pembuatan e-modul. Kegiatan selanjutnya yang dilakukan adalah kegiatan utama, yaitu pemberian materi mengenai pembuatan e-modul interaktif berbasis CLIL untuk android menggunakan Sigil Software.

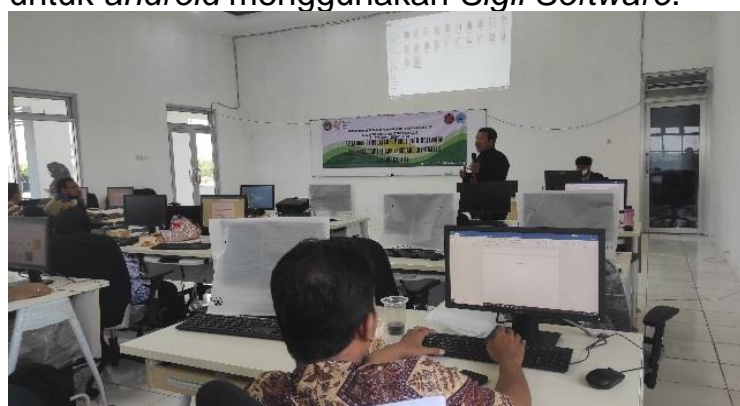

Gambar 4. Pendampingan Pembuatan E - Modul (Sumber : Pribadi).

E-modul interaktif menggunakan Sigil Software adalah modul dalam bentuk digital, yang dapat terdiri dari teks, gambar, video, video animasi, simulasi, permainan, dan latihan soal, sehingga membuat siswa lebih interaktif dalam pembelajaran (Liana et al., 2019).

Dalam kegiatan pendampingan ini, peserta diberikan kebebasan untuk membawa atau membuat modul nya sendiri. Sehingga pada saat pelaksanaan praktik pembuatan $e$ modul, peserta akan diarahkan dan didampingi oleh tim PKM secara langsung untuk mengkonversi modul yang telah dibuat menjadi bentuk e-modul menggunakan Sigil Software. Berikut alur yang harus dilakukan untuk membuat e-modul menggunakan Sigil Software.

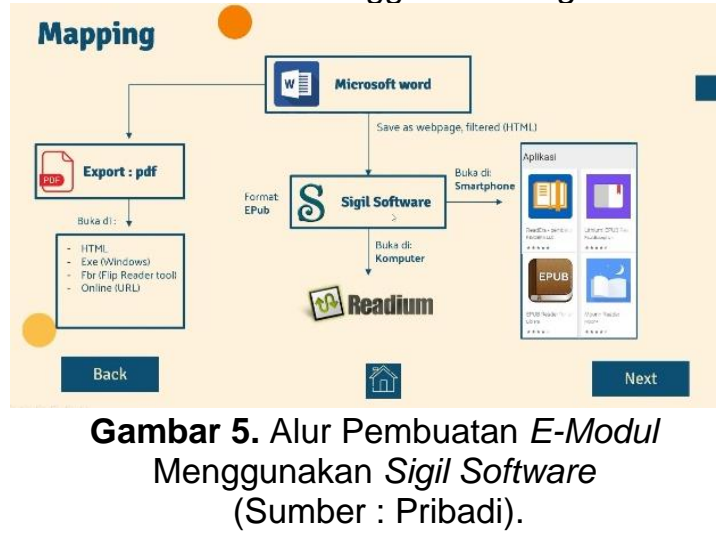

Setelah pemateri memberikan ceramah mengenai Sigil Software dan alur peenggunaannya, kegiatan selanjutnya adalah peserta pendampingan ditugaskan untuk mempraktikan pembuatan daro modul menjadi e-modul. Praktik pembuatan e-modul dilakukan agar peserta pendampingan mendapatkan manfaat kegiatan secara langsung. 


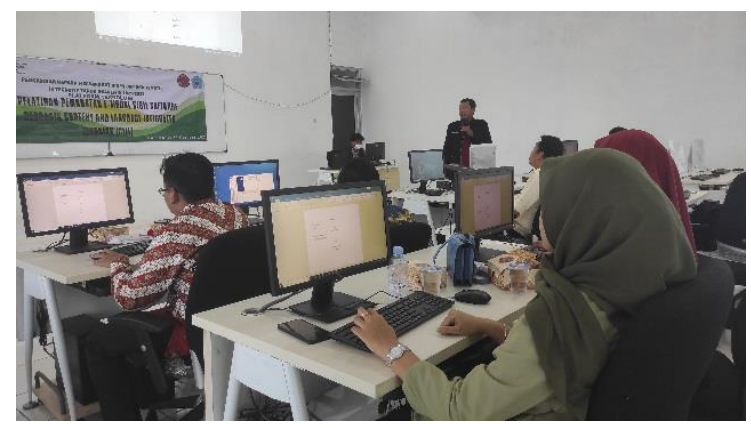

Gambar 6. Praktik Pembuatan E-Modul Menggunakan Sigil Software

(Sumber : Pribadi).

Adapun output dari pelaksanaan program ini adalah e-modul interaktif. E-Modul interaktif yang dibuat dapat diakses oleh siapapun, khususnya siswa. Nantinya e-modul dapat digunakan oleh guru dan siswa untuk menunjang proses pembelajaran didalam kelas. Hal tersebut bertujuan agar siswa lebih siap dan termotivasi untuk mengikuti pembelajaran yang diberikan oleh guru (Chen et al., 2010). Selaras dengan hal itu maka tujuan pembelajaran dapat tercapai dengan baik. Berikut contoh tampilan hasil pembuatan e-modul interaktif menggunakan Sigil Software.

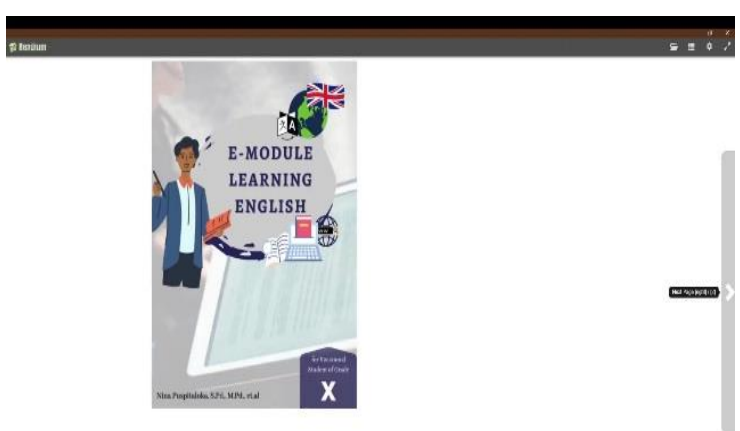

Gambar 7. Tampilan Contoh E-Modul (Sumber : Pribadi).

Setelah praktik pembuatan e-modul selesai, akhir dari kegiatan ini adalah sesi tanya jawab. Peserta pendampingan diberikan kesempatan untuk bertanya kepada pemateri. Ini dilakukan bertujuan untuk memastikan bahwa peserta dapat memahami materi yang telah disampaikan oleh pemateri dengan baik. Pada sesi tanya jawab ini, ada beberapa pertanyaan yang disampaikan oleh peserta. Setiap pertanyaan langsung dapat dijawab oleh pemateri.

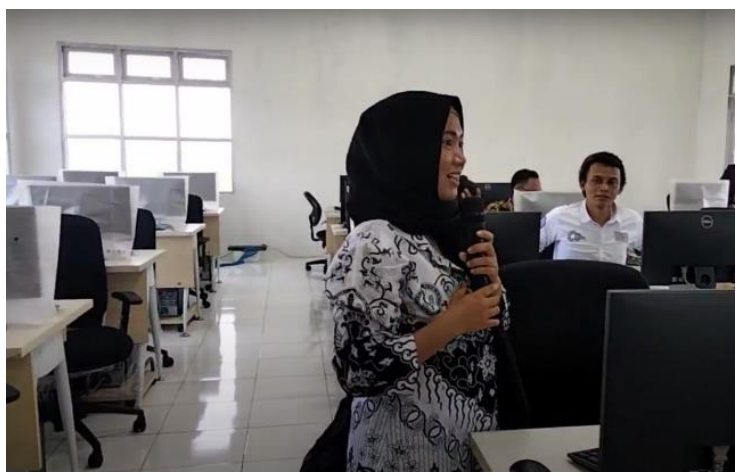

Gambar 8. Sesi Tanya Jawab

(Sumber : Pribadi).

Setelah seluruh rangkaian acara selesai, tim PKM melakukan evaluasi terhadap kegiatan tersebut. Evaluasi dilakukan guna melihat sejauh mana keberhasilan kegiatan PKM yang telah dilakukan. Adapun evaluasi yang dilakukan yaitu berupa wawancara langsung kepada seluruh peserta pelatihan. Selain itu juga tim PKM melihat tingkat partisipasi seluruh peserta saat pelaksanaan kegiatan. Hasil dari PKM ini adalah seluruh rangkaian kegiatan pendampingan pembuatan e-modul menggunakan Sigil Software dapat berjalan dengan lancar dan diikuti dengan baik oleh seluruh peserta. Peserta terlihat antusias dalam mengikuti tahapan-tahapan kegiatan yang dilakukan. Dari seluruh rangkaian kegiatan yang telah dilakukan, tim Pengabdian Kepada Masyarakat dapat melihat bahwa seluruh materi yang disampaikan dapat diterima. Selain itu, peserta juga dapat mempraktikkannya dengan baik hingga akhir kegiatan. Selain itu, berdasarkan hasil pengamatan yang dilakukan selama kegiatan, program pendampingan ini tidak ditemui kendala yang berarti baik kendala teknis maupun kendala lainnya. Kegiatan pelatihan dapat berjalan dengan lancar meski butuh waktu untuk membimbing peserta dalam mempraktikkan setiap tahapan yang dijelaskan oleh tim pelaksana dikarenakan peserta masih baru mengenal dan menggunakan Sigil Software sebagai alat bantu untuk membuat $e$ modul interaktif. Selain itu, berdasarkan seluruh rangkaian kegiatan dapat diketahui bahwa pendampingan pembuatan e-modul menggunakan Sigil Software telah memberikan dampak positif kepada peserta dimana peserta mendapatkan pengetahuan dan keterampilan baru mengenai pemanfaatan teknologi untuk memaksimalkan pembelajaran. Secara keseluruhan program pendampingan yang telah dilaksanakan dapat dikatakan berhasil karena dapat mencapai tujuan dan manfaat dari kegiatan pengabdian ini kepada peserta. 


\section{SIMPULAN DAN SARAN}

Berdasarkan kegiatan yang telah dilakukan, dapat disimpulkan bahwa 1) Pelaksanaan pendampingan sangat mendukung pengembangan pengetahuan guru Bahasa Inggris SMK khususnya dalam pembuatan e-modul menggunakan Sigil Software, 2) Peserta sangat antusias dalam mengikuti rangkaian kegiatan pendampingan. Hal ini memberikan informasi bahwa sangat perlu dilakukan bentuk pendampingan seperti ini untuk meningkatkan kualitas guru. Selain itu peserta juga mendapatkan pengetahuan baru, nilai tambah, keterampilan baru, dan kompetensi baru dalam meningkatkan kualitas pembelajaran Bahasa Inggris sesuai dengan kebutuhan siswa kejuruan.

Program Pengabdian kepada Masyarakat ini merupakan sebuah kegiatan yang dapat memberikan wawasan baru dalam proses pembelajaran dengan menggunakan $e-$ modul berbasis ICT, sehingga diharapkan pendampingan pembuatan e-modul menggunakan sigil software ini dapat juga diterapkan tidak hanya di SMK saja tetapi juga dapat di terapkan sekolah-sekolah lain di Kabupaten Karawang.

\section{UCAPAN TERIMAKASIH}

Penulis menyampaikan penghargaan yang tinggi dan terima kasih kepada Lembaga Penelitian dan Pengabdian Masyarakat (LPPM) Universitas Singaperbangsa Karawang, Jawa Barat dan SMK SAINTEK Nurul Muslimin Batujaya, Karawang.

\section{DAFTAR RUJUKAN}

Bahri, Humaedi, Rizal, Misnah, Gamar, M. M., \& Riang, A. D. (2021). Utilization of ICTBased Learning Media in Local History Learning. Journal of Physics: Conference Series. 1764 (012079), 1-6. https://doi.org/10.1088/17426596/1764/1/012079

Bllaca, N. (2016). Smartphone use in English Language Learning. International Conference on Linguistics, Literature and Culture, July, 305-315. https://dspace.aabedu.net/handle/123456789/306

Chen, Z., Stelzer, T., \& Gladding, G. (2010). Using multimedia modules to better prepare students for introductory physics lecture. Physical Review Special Topics Physics Education Research, 6(1), 5. https://doi.org/10.1103/PhysRevSTPER.6 .010108

Fitri, A. (2019). Pengembangan E-Modul Berbantuan Sigil Software Pada Materi Relasi Dan Fungsi (Vol. 53, Issue 9).
UNIVERSITAS ISLAM NEGERI RADEN INTAN LAMPUNG.

Liana, Y. R., Ellianawati, \& Hardyanto, W. (2019). Pengembangan E-Modul Interaktif Berbasis Android Menggunakan Sigil Software pada Materi Listrik Dinamis. Seminar Nasional Pascasarjana Universitas Negeri Semarang, 926-932.

Masyhud, M. (2021). Pelatihan Dan Pendampingan Pembuatan Bahan Ajar Bahasa Inggris Bagi Guru Sekolah Menengah Kejuruan Muhammadiyah 1 Kota Batu. SELAPARANG Jurnal Pengabdian Masyarakat Berkemajuan, 4(2), 483. https://doi.org/10.31764/jpmb.v4i2.4042

Puspitaloka, N. (2020). Pelatihan Basic English for Computing untuk Siswa SMK Teksas Purwakarta. Jurnal Anadara Pengabdian Kepada Masyarakat, 2(1).86-90

Samodro, N. U. (2019). Pengembangan Media Pembelajaran Berbasis Tablet Android Pada Pelajaran Bahasa Inggris di SMK Harmoni Batam [Universitas Negeri Padang]. In e-Repository Dosen Universitas Negeri Padang. http://ejournal.unigamalang.ac.id/index.p $\mathrm{hp} / \mathrm{RDOS} /$ article/view/378

Sari, F. A. (2020). Pelatihan penggunaan aplikasi Edmodo dalam menunjang proses pembelajaran di SMAN 1 Ciomas. Jurnal Abdikarya, 2(2), 83-96.

Sarmini, S., Pambayun, N. L. P., \& Nurdewanti, N. P. (2021). Pelatihan Pembuatan Bahan Ajar Menggunakan Filmora Kepada Guru Madrasah Aliyah (Ma) Tanbihul Ghofiliin Banjarnegara. SELAPARANG Jurnal Pengabdian Masyarakat Berkemajuan, 4(3), 672. https://doi.org/10.31764/jpmb.v4i3.4871

Surjono, H. D., \& Susila, H. R. (2013). Pengembangan multimedia pembelajaran bahasa inggris untuk SMK. Jurnal Pendidikan Vokasi, 3(1), 45-52. https://doi.org/10.21831/jpv.v3i1.1576 